\title{
PEDIATRIC PATIENTS WITH ACUTE LYMPHOBLASTIC LEUKEMIA
}

\author{
Mohamed Elshinawy ${ }^{(1,2)}$, Abdulhakim AlRawas ${ }^{(1)}$, Yasser Wali ${ }^{(1,2)}$
}

\section{Background and Aims}

Asparaginase is an essential drug for treatment of pediatric acute lymphoblastic leukemia (ALL).

We aim to review the clinical characteristics, management and prognosis of asparaginaserelated adverse reactions in Omani children with ALL.

\section{Methods and Results}

A retrospective cohort study of all children diagnosed with ALL during the period January 2006 through January 2018.

Out of 198 pediatric patients with ALL, 11 children (8 males and 3 females) developed severe asparaginase-related adverse effects, constituting $5.6 \%$ of the total number of patients. Severe full blown pancreatitis was encountered in only one patient $(0.05 \%)$. Two patients developed severe anaphylactic reaction, and then shifted to erwinia asparaginase. Notably, eight of our patients developed asparaginase-related cerebral venous sinus thrombosis, evidenced by contrast-enhanced MRI. The mean duration of stroke diagnosis was $(6 \pm 2.1)$ days after the last asparaginase injection. All were managed conservatively with anticoagulation using heparin. Two of these patients have had a recurrence upon re-challenge, despite prophylaxis. Remarkably, seven patients (7/8) survived without any neurological sequelae.
Unfortunately, a 30 month-old boy developed permanent right-sided hemiplegia secondary to extensive superior sagittal sinus thrombosis, which has been uniquely associated with massive left-sided fronto-parietal hemorrhage and midline shift (Figure). This patient required ICU admission and underwent a pressure-relieving craniectomy surgery.

In addition, 22 patients developed mild asparaginase-related side effects in the form of transient hyperglycemia that required insulin in 17 patients and skin reactions in 5 patients.

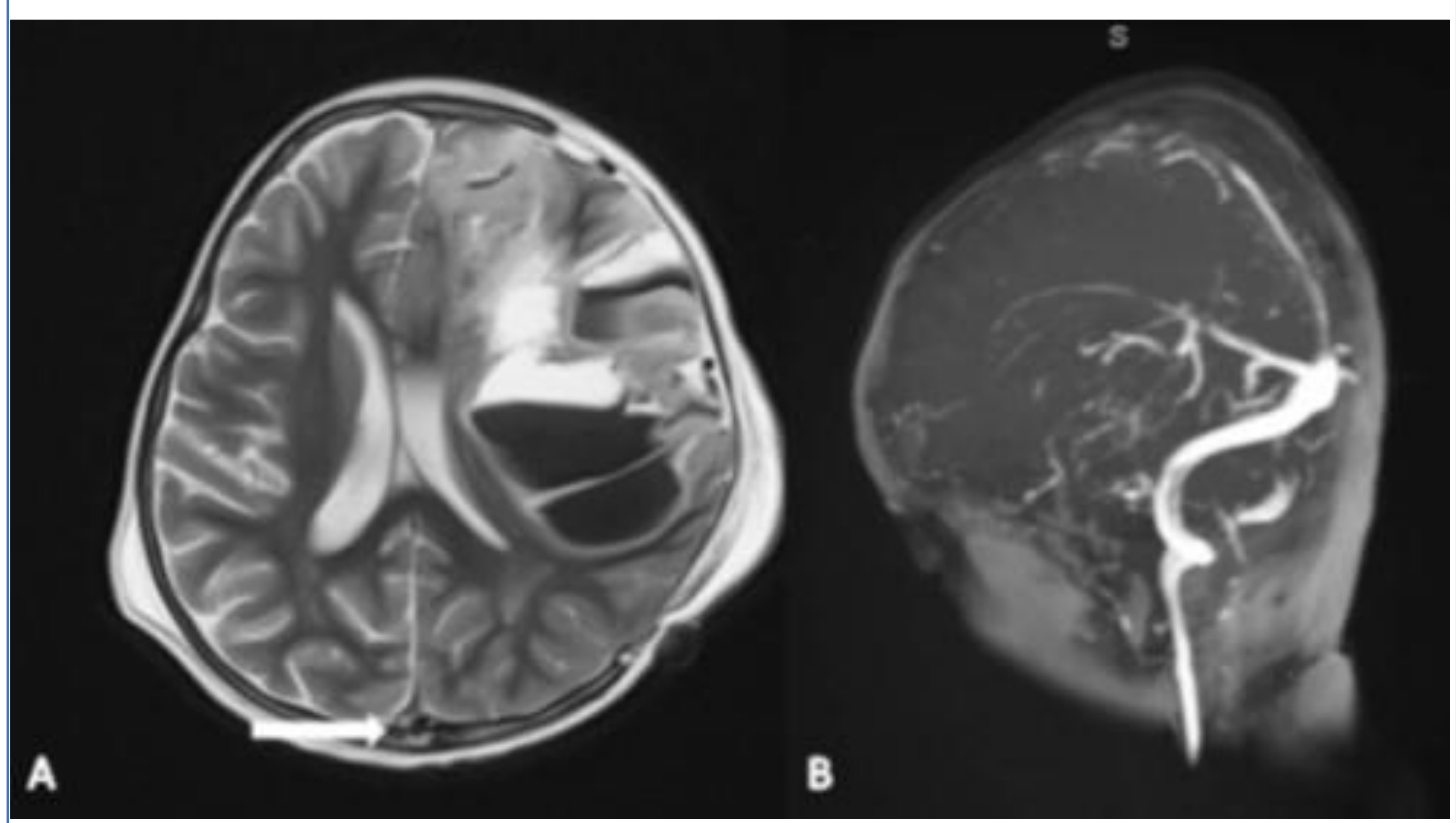

\section{$\underline{\text { Conclusion }}$}

Most of asparaginase-induced adverse reactions are transient and self-limited. However, a high index of suspicion is needed for early detection of intracranial thrombotic complications. 